\title{
Investigation into River Sediments Toxicity as a Result of Inappropriate Waste Disposal
}

\author{
Lívia R. Souza and Ana Cláudia Q. Ladeira \\ Center for Development of Nuclear Technology (CDTN) Avenida Antonio Carlos 6627, Campus UFMG, \\ 31270901 Belo Horizonte, MG, Brazil \\ Correspondence should be addressed to Ana Cláudia Q. Ladeira; acql@cdtn.br
}

Received 30 November 2012; Revised 4 February 2013; Accepted 8 February 2013

Academic Editor: Brajesh Dubey

Copyright ( 2013 L. R. Souza and A. C. Q. Ladeira. This is an open access article distributed under the Creative Commons Attribution License, which permits unrestricted use, distribution, and reproduction in any medium, provided the original work is properly cited.

\begin{abstract}
Sediments of the São Francisco River basin (Brazil) were investigated to determine the environmental consequences of incorrect disposal of wastes generated by a zinc industry. Surface sediments were characterized by X-ray diffraction (XRD) and chemically analyzed by X-ray fluorescence (XRF). Total organic carbon (TOC), acid volatile sulfides (AVSs), and simultaneously extracted metals (SEMs) were also determined. AVS/SEM procedure was employed to assess the bioavailability of the metals in sediments. $\mathrm{XRD}$ analyses indicated that the main phases in the sediments were kaolinite and quartz. The total concentration of $\mathrm{Zn}$ and $\mathrm{Pb}$, near the old industrial discharge point, indicated high levels of contamination according to the sediment quality guidelines (SQGs). According to the AVS/SEM criteria, despite the high levels of zinc and lead in the sediments, the toxicity resulting from these metals is unlikely in most of the samples. However, in one of the samples, collected near the old industrial discharge point, the toxicity is uncertain-according to the USEPA criteria.
\end{abstract}

\section{Introduction}

The São Francisco River, one of the most important Brazilian rivers, runs through seven Brazilian States and its basin covers $7.5 \%$ of country's territory. In the southern part of the São Francisco basin a zinc mining is the main responsible industry for the environmental impacts [1]. One of the main impacts occurred up to the 1980s and was caused mainly by incorrect disposal of solid wastes, which were disposed right on the soil. In fact, the wastes were disposed in piles along the river banks for over 30 years and ended up in river bed which aggravated the situation. In 1983, the zinc industry built its first tailings dam; however, it did not have protection layers to prevent seepage of the contaminants from the wastes into the ground or groundwater. More recently, corrective measures are being implemented by the industry in accordance to the requirements of the Brazilians environmental agencies [24]. Nevertheless, the environmental impact which occurred before 2002 still poses a threat to the water, sediments, and soil quality.

The aforementioned area has been monitored extensively by the governmental agencies with assessment of the physical and chemical parameters of the water and sediments; however, the bioavailability of metals is still poorly investigated. For the assessment of potential bioavailability of metals in river sediments, a traditional method is the AVS/SEM which determines the acid volatile sulfide (AVS) and the metals that are solubilized during acidification step (simultaneously extracted metals-SEMs). As a precipitant of toxic metals, sulfide plays a key role in controlling bioavailability of metals in anoxic sediments [5]. The sulfides are formed by microbial reduction of $\mathrm{SO}_{4}{ }^{2-}$ and the majority of them consisted of free sulfides, $\mathrm{FeS}$, and $\mathrm{Fe}_{3} \mathrm{~S}_{4}$, as well as low solubility metal sulfides such as copper, nickel, zinc, cadmium, and lead sulfides $[6,7]$. An understanding of the distribution of dissolved species in AVS is important to comprehend the biogeochemistry of sulfidic natural systems. The equilibrium partitioning sediment benchmark (ESB) document [8] describes procedures to derive concentrations of metal mixtures in sediment which are protective of the presence of benthic organisms. The equilibrium partitioning theory predicts the metals partition in sediment between acid volatile sulfide (AVS), pore water, benthic organisms, and other sediment phases such as organic carbon. Biological responses of benthic organisms 
TABLE 1: Geographic coordinates and description of the sites where the sediments were collected.

\begin{tabular}{lccl}
\hline Sample & Latitude & Longitude & Description \\
\hline PSF01 & $18^{\circ} 12^{\prime} 37.1^{\prime \prime}$ & $45^{\circ} 15^{\prime} 52.8^{\prime \prime}$ & São Francisco River, upstream of zinc industry. \\
PSF03 & $18^{\circ} 10^{\prime} 49.5^{\prime \prime}$ & $45^{\circ} 14^{\prime} 20.5^{\prime \prime}$ & São Francisco River, near the industry water catchment. \\
PSF05 & $18^{\circ} 11^{\prime} 01^{\prime \prime}$ & $45^{\circ} 14^{\prime} 41^{\prime \prime}$ & São Francisco River, opposite the tailing dam. \\
PSF06 & $18^{\circ} 10^{\prime} 42.4^{\prime \prime}$ & $45^{\circ} 14^{\prime} 16.8^{\prime \prime}$ & São Francisco River, downstream of the industrial effluent discharge. \\
PCS01 & $18^{\circ} 10^{\prime} 47^{\prime \prime}$ & $45^{\circ} 14^{\prime} 15.3^{\prime \prime}$ & Consciência Creek, near the old industrial effluent discharge. \\
PLV01 & $18^{\circ} 10^{\prime} 19.3^{\prime \prime}$ & $45^{\circ} 11^{\prime} 49.9^{\prime \prime}$ & Lavagem Creek, near the new industrial effluent discharge. \\
\hline
\end{tabular}

to the metals are different across sediments when the metals concentrations are expressed on a dry weight basis but similar when expressed on a $\sum$ SEM - AVS basis. The presence of metals such as cadmium, copper, lead, nickel, silver, and zinc in sediments may not cause direct toxicity to benthic organisms if the $\sum$ SEM - AVS is $\leq 0.0$. However, if the $\sum$ SEM - AVS is $>0.0$, toxic effects may occur with increasing severity as the degree of exceedance increases.

Many other studies have shown that the toxicity to benthic organisms does not occur when the concentration of acid volatile sulfides is greater than the sum of simultaneously extracted metals from the sediment [6-8]. Thus,

$$
\begin{aligned}
& \sum \text { SEM > AVS: potentially toxic sediment, } \\
& \sum \text { SEM < AVS: non potentially toxic sediment. }
\end{aligned}
$$

This assumption is based upon the low solubility of the metal sulfides $(\mathrm{Cd}, \mathrm{Cu}, \mathrm{Ni}, \mathrm{Pb}$, and $\mathrm{Zn}$ ) which are removed from the soluble fraction by precipitation [9]. However, it should be considered that the sequence of precipitation depends on the solubility of the solid sulfide. According to the sulfide solubility product $(K)$, the order of solubility from the lowest to the highest soluble is $K_{\mathrm{CuS}}<K_{\mathrm{PbS}}<K_{\mathrm{CdS}}<K_{\mathrm{ZnS}}<$ $K_{\mathrm{NiS}}$ [7]. This means that the first sulfide to precipitate is CuS, and once there is no $\mathrm{Cu}$ in solution, but enough sulfide, the precipitation of $\mathrm{PbS}$ occurs.

The literature $[5,8]$ reports three criteria to express the relationship between acid volatile sulfides and metal toxicity: (i) the difference between SEM and AVS ( $\sum$ SEM - AVS), (ii) the ratio of SEM to AVS ( $\sum$ SEM/AVS), and (iii) the SEM to AVS difference normalized by the fraction of total organic carbon (TOC) in a sediment ((SEM - AVS)/TOC). The latter considers the organic carbon in the sediments, once the organic matter is intrinsically related to the bioavailability of the metals.

The present work focuses on the investigation into river sediments toxicity in a region affected by the mining. In the past, environmental practices no longer tolerated were extensively used by the industry. Mineralogy as well as major and trace elements in the sediments of streams located in the mining area and in its surroundings was determined. Sediments were classified according to the canadian sediment quality Guidelines (SQGs) which provided scientific benchmarks,or reference points, for evaluating the potential for observing adverse biological effects in aquatic systems. To evaluate the bioavailability of the metals in the sediments, AVS-SEM and total organic carbon were determined and the results were analyzed according to the toxicity criteria proposed by USEPA.

\section{Experimental}

2.1. Study Area. Sediments were collected in the São Francisco River as well as in two tributaries-Consciência and Lavagem Creeks-located in the municipality of Três Marias, MG, Brazil. The sampling sites are described in Table 1 and they are the same used by the Brazilian Environmental Agency to monitor the area. After the sediments were dredged, the samples were refrigerated at $4^{\circ} \mathrm{C}$ before the analyses.

2.2. Methods. X-ray diffraction (XRD) was used to identify the minerals present in the sediments. The analyses were performed using a Rigaku D/Max Ultima diffractometer with automatic slit, $\mathrm{Cu} \mathrm{K} \alpha$ radiation at $40 \mathrm{kV}$ and $30 \mathrm{~mA}$. The XRD patterns were collected in the $4-80^{\circ} 2 \theta$ range and counts were recorded at $4^{\circ} 2 \theta \mathrm{min}^{-1}$. The data was interpreted using the Jade 9 software.

Quantitative analyses of the metals were carried out in an energy dispersive X-ray fluorescence spectrometer, Shimadzu EDX-720, fitted with a rhodium X-ray tube at $15 \mathrm{keV}$ (for $\mathrm{Na}$ to $\mathrm{Sc}$ ) and $100 \mu \mathrm{A}$, under air atmosphere, $\mathrm{Si}(\mathrm{Li})$ detector, and a $10 \mathrm{~mm}$ collimator. The elements determined were $\mathrm{Zn}, \mathrm{Cu}$, and $\mathrm{Pb}$.

Samples were submitted to AVS-SEM assays, according to procedures adapted from the analytical draft EPA 821R-91-100 (USEPA, 1991). Wet sediments were weighed and placed into reaction flasks with $100 \mathrm{~mL}$ of Milli-Q water which was deaerated by bubbling nitrogen for $10 \mathrm{~min}$ at a flow rate of $100 \mathrm{~cm}^{3} / \mathrm{min}$. After 20 minutes of nitrogen purging, $20 \mathrm{~mL}$ of $\mathrm{HCl}(6 \mathrm{M})$ was added and the system underwent nitrogen flow for 2 hours. The volatilized sulfides were purged from reaction flasks by $\mathrm{N}_{2}$ at a flow rate of $40 \mathrm{~cm}^{3} / \mathrm{min}$ and trapped into flasks containing $\mathrm{NaOH}$ solution $(0.5 \mathrm{M})$. After the generation of sulfide was completed, the suspension containing chloridric acid, corresponding to SEM, was filtered in a $0.45 \mu \mathrm{m}$ mixed cellulose membrane. The filtrate was sent to the determination of metals $(\mathrm{Cu}, \mathrm{Cd}, \mathrm{Pb}, \mathrm{Ni}$, and $\mathrm{Zn}$ ) by flame atomic absorption spectrometry, in a Varian AA240FS. For sulfide determination, the colorimetric method with methylene blue was used, and the absorbance was measured in a UV-VIS spectrophotometer Varian Cary 50 Conc. The total sulfur and carbon contents were analyzed by using 
TABLE 2: Total content of zinc, copper, and lead in sediment, thresholds for TEL, PEL, and detection limits (DLs).

\begin{tabular}{lccc}
\hline Sample & $\mathrm{Zn}$ & $\begin{array}{c}\mathrm{Cu} \\
\left(\mathrm{mg} \mathrm{kg}^{-1} \text { of sediment }\right)\end{array}$ & $\mathrm{Pb}$ \\
\hline PLV01 & 234 & 35 & 47 \\
PSF01 & 54 & 18 & 17 \\
PSF03 & 94 & 40 & 40 \\
PSF05 & 411 & 36 & 41 \\
PSF06 & 5900 & 74 & 222 \\
PCS01 & 8430 & 84 & 322 \\
D.L. & 10 & 10 & 10 \\
TEL & 120 & 19 & 30 \\
PEL & 270 & 110 & 110 \\
\hline
\end{tabular}

the LECO 444 LS elemental analyzer (LECO Corporation). In order to determine the organic carbon, the sample was dried at $60^{\circ} \mathrm{C}$ and an aliquot of hydrochloric acid $4 \mathrm{M}$ was added to the sediment in order to eliminate the inorganic carbon. Then, the sediment was dried again and the residual organic carbon was determined by the LECO.

Statistical analyses were performed using the Minitab 16 software package (Minitab Inc., USA).

\section{Results and Discussion}

According to Figure 1, all the samples presented similar XRD patterns and consisted mainly of kaolinite and quartz in a well-crystallized form. Small contents of muscovite were also observed.

The contents of metals in sediments determined by $\mathrm{XRF}$ are presented in Table 2. Since there are no specific guidelines for classifying sediments in Brazil, the Canadian guideline (SQGs-sediment quality guidelines) was used to assess the quality of the sediment [10]. The SQGs consider the threshold effect level (TEL) as being the concentration value below which adverse biological effects are expected to occur rarely, and the probable effect level (PEL) defines the level above which adverse effects are expected to occur frequently. By calculating TELs and PELs, three ranges of chemical concentrations are defined: (1) the minimal effect range within which adverse effects rarely occur (i.e., less than $25 \%$ of adverse effects occur below the TEL), (2) the possible effect range within which adverse effect occasionally occur (i.e., the range between the TEL and PEL), and (3) the probable effect range within which adverse biological effects frequently occur (i.e., more than $50 \%$ of adverse effects occur above the PEL).

The sample PSF01 presents metals concentrations ( $\mathrm{Zn}$, $\mathrm{Cu}$, and $\mathrm{Pb}$ ) below the TEL limit, indicating that adverse biological effects are hardly expected to occur. As this sampling site is located upstream of the zinc industry no contamination in that sediment is expected. The contents of copper and lead are above TEL and below the PEL for the samples PSF03 and PSF05 which indicate that adverse effects occasionally occur. For the sediment PLV01, located downstream of the new dam, the levels of all metals are below the PEL and above the TEL.
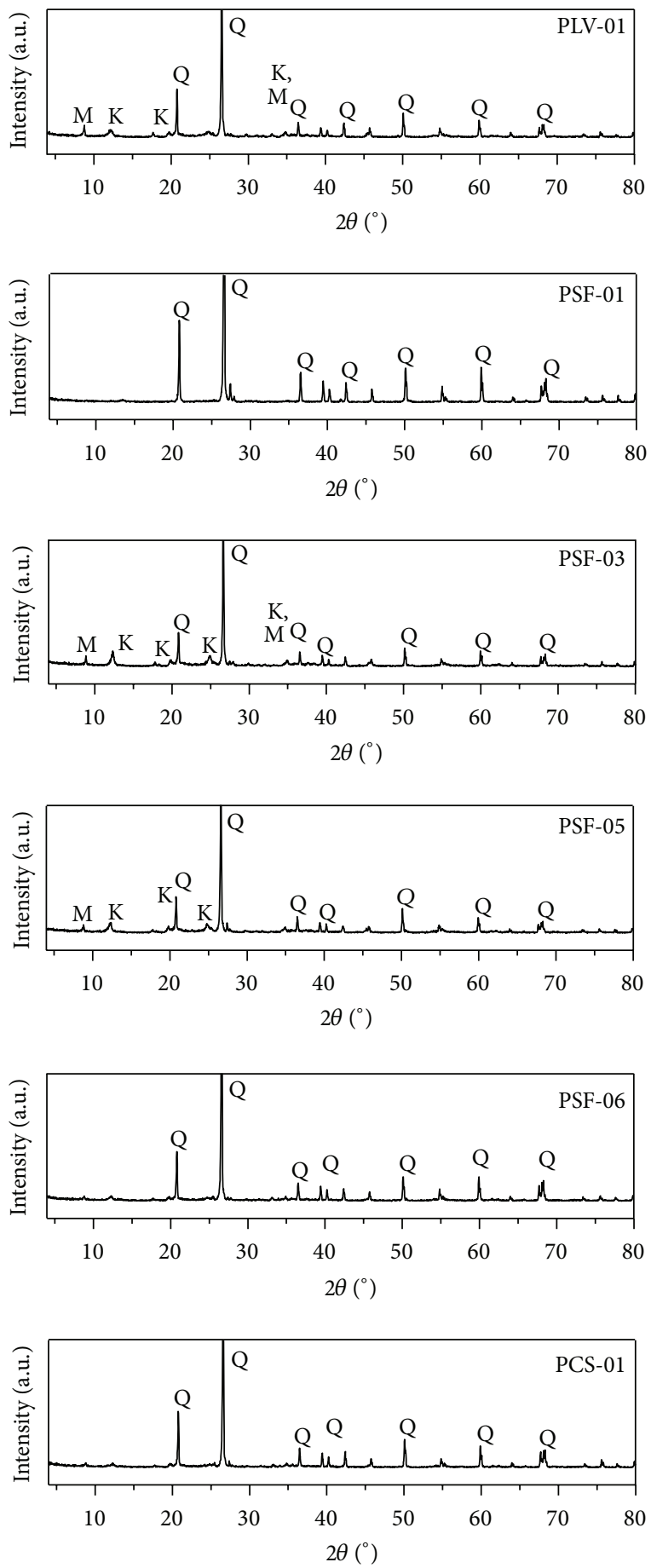

FIGURE 1: XRD patterns of bulk samples of sediments. $Q=$ quartz, $\mathrm{M}=$ muscovite, $\mathrm{K}=$ kaolinite.

However, it is important to point out that the concentration of metals in the PLV01 is higher than the concentrations found in the PSF01, the sediment collected upstream of the zinc industry, which suggest some impact in the area. In addition, the zinc concentration is above PEL for the samples PSF05, PSF06, and PCS01 indicating that adverse biological effects frequently occur. Similarly, PSF06 and PCS01 show a lead 
TABLE 3: Acid volatile sulfides (AVSs) ( $\mu \mathrm{mol} \mathrm{g}^{-1}$ of dry sediment), Simultaneously extracted metals (SEMs) ( $\mu \mathrm{mol} \mathrm{g}^{-1}$ of dry sediment), sum of extracted metals ( $\sum$ SEM), total sulfur $\left(\mu \mathrm{mol} \mathrm{g}^{-1}\right.$ of dry sediment), and total organic carbon (TOC) (\%).

\begin{tabular}{lcccccccccc}
\hline Sample & $\begin{array}{c}\text { TOC } \\
(\%)\end{array}$ & Sulfur & AVS & $\mathrm{Cu}$ & $\mathrm{Co}$ & $\begin{array}{c}\mathrm{Ni} \\
\left(\mu \mathrm{mol} \mathrm{g}^{-1}\right)\end{array}$ & $\mathrm{Pb}$ & $\mathrm{Zn}$ & $\mathrm{Cd}$ & $\sum$ SEM \\
\hline PSF01 & 0.53 & 14.98 & $<0.01$ & 0.04 & 0.05 & 0.05 & 0.01 & 0.22 & $<0.01$ & 0.37 \\
PSF03 & 0.29 & 38.25 & $<0.01$ & 0.18 & 0.19 & 0.08 & 0.06 & 0.63 & $<0.01$ & 1.14 \\
PSF05 & 0.8 & 43.47 & $<0.01$ & 0.18 & 0.19 & 0.06 & 0.08 & 5.26 & $<0.01$ & 5.77 \\
PLV01 & 0.98 & 43.05 & 0.01 & 0.11 & 0.12 & 0.08 & 0.08 & 2.45 & $<0.01$ & 2.84 \\
PSF06 & 0.89 & 67.69 & 0.01 & 1.15 & 1.24 & 0.07 & 1.47 & 129.51 & 0.3 & 133.74 \\
PCS01 & 1.06 & 64.96 & 1.93 & 1.52 & 1.63 & 0.26 & 1.98 & 132.4 & 0.4 & 138.19 \\
\hline
\end{tabular}

content greater than the PEL. Therefore, the contamination of the area by zinc and lead can lead to adverse biological effects.

The contents of AVS and $\sum$ SEM are presented in Table 3. The greatest content of AVS, approximately $61.8 \mathrm{mg} \mathrm{kg}^{-1}$ of dry sediment $\left(1.93 \mu \mathrm{mol} \mathrm{g}^{-1}\right)$, was observed in sample PCS01, collected in the surroundings of the old waste disposal site of the zinc industry. Once the effluents were released directly into Consciência Creek in the past-without previous treatment - the concentration of acid volatile sulfides at this site is the highest, and it may be a consequence of the improper discharging. The sample station PSF06 also presents high levels of AVS $\left(0.33 \mathrm{mg} \mathrm{kg}^{-1}\right.$ of dry sediment $-0.01 \mu \mathrm{mol} \mathrm{g}^{-1}$ ) but lower than the contents determined in the sample PCS01. No detectable concentrations of acid volatile sulfides were observed in the samples PSF01, PSF03, and PSF05. Although the AVS data for PCS01 and PSF06 are considered high if compared to the other samples of this study, the contents of sulfides in sediments worldwide, including Brazil, are relatively lower [11].

The contents of $\sum$ SEM vary largely in the samples (Table 3). Sediments PSF01, PSF03, and PSF05 collected in the São Francisco River upstream of the zinc industry and PLV01 located downstream of the new station of effluents discharge present low $\sum$ SEM, less than $6 \mu \mathrm{mol} \mathrm{g}^{-1}$. The samples PSF06 and PCS01 present $\sum$ SEM greater than $130 \mu \mathrm{mol} \mathrm{g}^{-1}$ and do not follow the trend presented by the other samples. In all samples, the predominant metal is zinc, followed by copper and cobalt. This is a relevant and positive fact, once zinc toxicity is lower than that of the other metals in the samples. The levels of lead in the samples are very low, close to those of nickel in PLV01, PSF01, PSF03, and PSF05; however, lead is slightly more concentrated in PSF06 and PCS01, presenting values of $1.5 \mu \mathrm{mol} \mathrm{g}^{-1}$.

Regarding the AVS-SEM procedure, two criteria were used for the assessment of sediment quality: (i) the difference ( $\sum$ SEM - AVS ) and (ii) the normalized difference ( $\sum$ SEM AVS)/TOC). The toxicity criteria, based upon the determination of acid volatile sulfide, simultaneously extracted metals, and organic carbon, are summarized in Table 4 [8].

The results of the assessment of sediment toxicity based upon the difference ( $\sum$ SEM - AVS) and the normalized difference $\left(\left(\sum\right.\right.$ SEM - AVS $\left.) / T O C\right)$ for the six samples are shown in Table 5.

According to Table 4, if the $\sum$ SEM-AVS is less than zero, no effects are expected to occur. However, all the samples
TABLe 4: Toxicity criteria according to AVS, SEM and TOC. (Adapted from [8]).

\begin{tabular}{ll}
\hline $\begin{array}{l}\text { SEM, AVS, and TOC } \\
\text { relationship }\end{array}$ & Toxicity criteria \\
{$\left[\frac{\sum \text { SEM }- \text { AVS }}{\text { TOC }}\right]<130$} & $\begin{array}{l}\text { Toxicity is not likely due to Cd, } \\
\text { Cu, Pb, Ni, and } \mathrm{Zn} .\end{array}$ \\
$130<\frac{\sum \text { SEM }- \text { AVS }}{\text { TOC }}<3000$ & $\begin{array}{l}\text { Toxicity is uncertain due to Cd, } \\
\text { Cu, Pb, Ni, and } \mathrm{Zn} .\end{array}$ \\
$\frac{\sum \mathrm{SEM}-\mathrm{AVS}}{\mathrm{TOC}}>3000$ & $\begin{array}{l}\text { Toxicity is likely due to Cd, Cu, } \\
\mathrm{Pb}, \mathrm{Ni} \text {, and } \mathrm{Zn} .\end{array}$ \\
$\sum$ SEM $-\mathrm{AVS} \leq 0$ & Nontoxic. \\
\hline
\end{tabular}

When $\sum$ SEM - AVS $>0$, organic carbon has to be taken into account according to the expressions in Table 4.

TABLE 5: Results for the assessment of sediment toxicity based upon the difference ( $\sum$ SEM - AVS) and the normalized difference (( $\sum$ SEM - AVS $) /$ TOC $)$.

\begin{tabular}{lcc}
\hline Sample & $\sum$ SEM - AVS & $\left(\sum\right.$ SEM - AVS $) /$ TOC \\
\hline PLV01 & 2.83 & 5.34 \\
PSF01 & 0.37 & 1.28 \\
PSF03 & 1.14 & 1.43 \\
PSF05 & 5.77 & 5.89 \\
PSF06 & 133.73 & 150.26 \\
PCS01 & 136.26 & 128.55 \\
\hline
\end{tabular}

have a $\sum$ SEM greater than the AVS. Although this approach $\left(\sum\right.$ SEM - AVS $\left.<0\right)$ can assure that no toxicity will occur with a high degree of certainty, it cannot predict whether toxicity will occur if $\sum \mathrm{SEM}-\mathrm{AVS}>0$ or $\sum \mathrm{SEM} / \mathrm{AVS}>1$ [12]. For that case, the literature suggests that organic carbon should be taken into account as it is an important source of extra binding capacity and, therefore, may also control the bioavailability $[8,13,14]$.

When the organic carbon content is considered, that is, (( $\sum$ SEM - AVS)/TOC), the toxicity is not likely to occur in sediments PLV01, PSF01, PSF03, PSF05, and PCS01, according to the USEPA 2005 criterion, since their concentrations are $<130 \mu \mathrm{mol} / \mathrm{g}_{\mathrm{oc}}$. It is noteworthy that most of the samples mentioned above present (SEM - AVS)/TOC $<6 \mu \mathrm{mol} / \mathrm{g}_{\text {oc }}$. However, the value for PCS01 is $129 \mu \mathrm{mol} / \mathrm{g}_{\mathrm{oc}}$, which is very close to the threshold limit, indicating that further attention is required. According to the aforementioned criterion, toxicity is uncertain only for the sample PSF06, once it was the only 


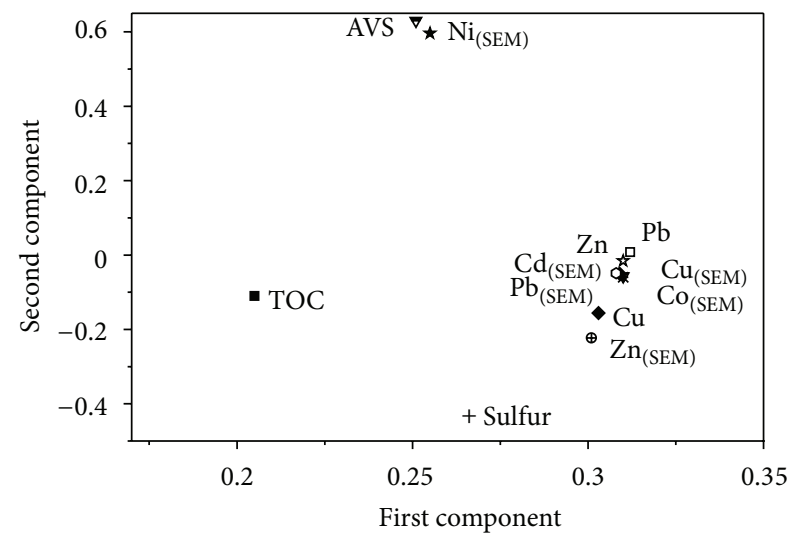

FIGURE 2: Loadings of variables on the plane defined by the principal components of PCA analysis for total metal concentration, organic matter, total sulfur, AVS, and SEM in sediments.

sediment to present values greater than $130 \mu \mathrm{mol} / \mathrm{g}_{o c}$. The guideline value to likely toxicity is $3000 \mu \mathrm{mol} / \mathrm{g}_{\mathrm{oc}}$. Despite the fact that the concentration of zinc in samples PCS01 and PSF06 is well above the PEL, the toxicity due to $\mathrm{Zn}$ is not likely in PCS01 and uncertain in PSF06, once the sulfide and organic matter are taken into account. This result is consistent with the literature that reports that total zinc concentrations in sediment do not show any relationship to the benthic macroinvertebrate effects [12].

Detailed statistical analyses of the observations were carried out to determine the interrelationship between the sources of pollution and contamination. Initially, data were analyzed using the principal component analysis (PCA) to provide an overview of their behaviors. Two-factor principal components for the loads were extracted for the 12 variables in the sediments corresponding to cumulative variance of $92.9 \%$. Factor 1 accounted for $85.6 \%$ of the total variance explained and factor 2 explained $7.3 \%$. The factor loading plot (Figure 2) shows three distinct groups: the main one includes total sulfur, copper, cobalt, lead, and zinc simultaneously extracted as well as total zinc, lead, and copper. The second group includes acid volatile sulfide and nickel simultaneously extracted, and the third, the TOC.

The scores (sampling sites) plots of PCA of the sediment samples (Figure 3) were used to identify a possible metal source. The main group in the plot includes the sampling site PSF-01, PSF-03, PSF-05, and PLV-01 with small influence of the mining activities. Sediments PCS-01 and PSF-06 are not grouped and show great influence of $\mathrm{PCl}$ due to its high contents of metals and total sulfur. The site PCS- 01 has the most contribution of PC2 mainly due to the AVS.

Hierarchical cluster analysis (CA) was applied to the sampling sites in order to provide an understanding of the similarities amongst them. The dendrograms with single linkage Euclidean distances are shown in Figure 4. The samples PSF-01 and PSF-03 form the cluster with the shortest linkage distance. The next link includes PLV-01 followed by PSF- 05 . Those four samples form a group that can be associated with

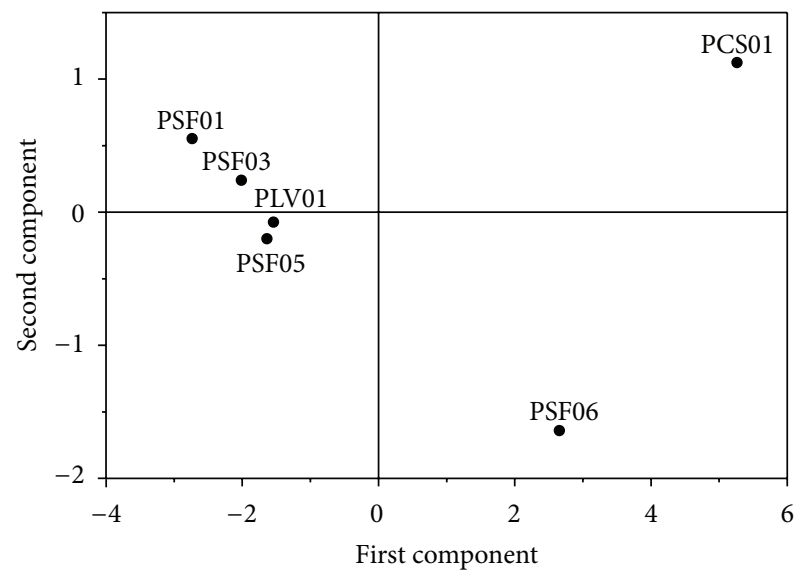

FIGURE 3: Scores of sampling sites on the plane defined by the principal components of PCA analysis for total metal concentration, organic matter, total sulfur, AVS, and SEM in sediments.

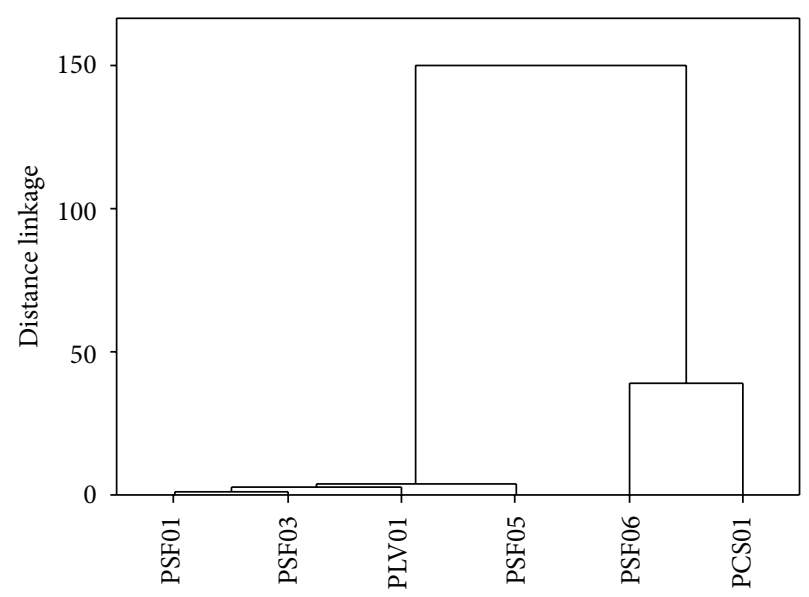

FIGURE 4: Dendrogram showing clustering of the studied sampling sites for total metal concentration, organic matter, total sulfur, AVS, and SEM in sediments.

the not likely toxicity, confirming the classification based on the toxicity criteria proposed by USEPA. The sites PSF-06 and PCS-01 show the furthest cluster and are distinguished from the rest due to the great influence of the contaminants. However, they are not considered similar because their linkage distance is too long. This fact corroborates the analyses of PCA as well as the toxicity criteria proposed by USEPA. Finally, it can be suggested that the PSF-06 and PCS-01 are the main sites impacted due to the incorrect disposal of the wastes. So, they should be prioritized during the remediation, monitoring, and controlling actions.

Similar results were reported in the literature for that region $[3,4,15]$. Geochemical, toxicity test, and bioavailability studies showed that some sediments collected near the old effluent discharge are most likely to present adverse effects on biota, associated with elevated contents of zinc, lead, and cadmium $[4,15]$. In a study of sediments collected in the vicinity of the new dam, which corresponds to the point 
PLV01, the levels of metals in sediments determined through AVS-SEM are not high enough as to cause deleterious effects to the biota, as discussed elsewhere [3]. However, the contents of zinc, copper, and lead determined in the present work are slightly greater than those reported by the previous researchers. In both works, the contents of AVS are greater than SEM, implying that the natural system is able to assimilate the impact that could come from this kind of contamination. Monitoring studies should still be carried out for a long time to verify this possibility.

Beside the acid volatile sulfides, sulfur may be present in sediments in other forms like the pyritic fraction not extracted by the $\mathrm{HCl}$, elemental S, organic $\mathrm{S}$, and the sulfate present in interstitial water or precipitated. Therefore, speciation studies are necessary to estimate the distribution of all these species in the samples. It can be seen from Table 4 that the total sulfur in PSF01-the background sample in this study-is around $15 \mu \mathrm{mol} \mathrm{g}^{-1}$. The sulfur in this sample is mainly sphalerite, pyrite, and barite, which are the mineralogical forms of the sulfur in the soil of this region [16]. In the other samples, the total sulfur is greater than the background sample, varying from 38 to $65 \mu \mathrm{molg}^{-1}$. It is suggested that the increase in the sulfur content is related to the negligent procedures adopted by the industry in the past. However, as already mentioned, the sediments can act as a sink of contaminants once the sulfate can be reduced in anoxic conditions forming a metal sulfide which attenuates the metals concentration.

\section{Conclusions}

The main minerals found in the sediments are kaolinite, quartz, and small amounts of muscovite, according to the mineralogical characterization. Chemical analysis showed that the total concentration of zinc is above PEL at the sampling site PSF-06 from the São Francisco River, near the old waste disposal site, and also in the sampling site PCS-01 from the Consciência Creek indicating that adverse effects are expected to occur frequently.

The bioavailability of the metals in sediments, according to the AVS-SEM procedure, indicated that the sampling site PCS-01 from the Consciência Creek presented high levels of acid volatile sulfur (AVS).

Elevated contents of metals were dissolved by SEM procedure in the sampling sites PSF-06 and PCS-01 from the São Francisco River and the Consciência Creek, respectively. For the other samples, the contents of metals simultaneously extracted (SEM) are close to the content of the total metals, indicating the prevalence of more soluble forms. According to the USEPA criterion, despite the high levels of zinc in some sediments only sample PCS06 presents uncertain toxicity, whereas for all others the toxicity is not likely.

\section{Conflict of Interests}

The authors declare that they have no direct financial relation with any commercial identity aforementioned in this paper that might lead to a conflict of interests.

\section{Acknowledgments}

The authors would like to thank FAPEMIG and CNPq (INCTAcqua) for the financial support.

\section{References}

[1] W. M. Trindade, A. H. Horn, and E. V. Ribeiro, "Heavy metal concentrations in sediments of the São Francisco river between Tres Marias and Pirapora-MG: geochemistry and classification of environmental risk," Geonomos, vol. 20, no. 1, pp. 64-75, 2012 (Portuguese).

[2] M. R. Oliveira, Investigação da Contaminação por Metais Pesados da Água e do Sedimento de Corrente nas margens do Rio São Francisco e tributários, a jusante da Represa da Cemig, no município de Três Marias, Minas Gerais [D. Sc. Thesis], Universidade Federal de Minas Gerais, Brazil, Minas Gerais, Brazil, 2010.

[3] V. K. Saraiva, M. R. L. Do Nascimento, H. E. L. Palmieri, and V. M. F. Jacomino, "Evaluation of sediment quality-case study: sub-watershed of espírito santo stream, affluent of the São Francisco River," Quimica Nova, vol. 32, no. 8, pp. 1995-2002, 2009 (Portuguese).

[4] M. V. T. Gomes, A. S. Costa, C. A. B. Garcia, E. A. Passos, and J. Do Patrocínio Hora Alves, "Concentrations and geochemical associations of $\mathrm{Pb}$ and $\mathrm{Zn}$ in sediments of the river São Francisco impacted by wastes from industrial zinc production," Quimica Nova, vol. 33, no. 10, pp. 2088-2092, 2010 (Portuguese).

[5] U.S. EPA, "Draft Analytical Method for Determination of Acid Volatile Sulfide and Selected Simultaneously Extractable Metals in Sediment," EPA 821-R-91-100, Office of Research and Development, Washington, DC, USA, 1991.

[6] T. Jong and D. L. Parry, "Heavy metal speciation in solid-phase materials from a bacterial sulfate reducing bioreactor using sequential extraction procedure combined with acid volatile sulfide analysis," Journal of Environmental Monitoring, vol. 6, no. 4, pp. 278-285, 2004.

[7] D. M. Di Toro, J. D. Mahony, D. J. Hansen, K. J. Scott, A. R. Carlson, and G. T. Ankley, "Acid volatile sulfide predicts the acute toxicity of cadmium and nickel in sediments," Environmental Science and Technology, vol. 26, no. 1, pp. 96-101, 1992.

[8] U.S. EPA, "Procedures for the Derivation of Equilibrium Partitioning Sediment Benchmarks (ESBs) for the Protection of Benthic Organisms: Metal Mixtures (Cadmium, Copper, Lead, Nickel, Silver and Zinc)," EPA 600-R-02-011, Office of Research and Development, Washington, DC, USA, 2005.

[9] J. W. Morse and D. Rickard, "Chemical dynamics of sedimentary acid volatile sulfide," Environmental Science \& Technology, vol. 38, no. 7, pp. 131A-136A, 2004.

[10] CCME-Canadian Council of Ministers of the Environment, "Canadian Sediments Quality Guidelines for the Protection of Aquatic Life: Summary tables update," Canadian Environmental Quality Guidelines, 2002.

[11] E. Fagnani, J. R. Guimarães, A. A. Mozeto, and P. S. Fadini, "Acid volatile sulfides and simultaneously extracted metals in the assessment of freshwater sediments," Química Nova, vol. 34, no. 9, pp. 1618-1628, 2011 (Portuguese).

[12] G. A. Burton, L. T. H. Nguyen, C. Janssen et al., "Field validation of sediment zinc toxicity," Environmental Toxicology and Chemistry, vol. 24, no. 3, pp. 541-553, 2005.

[13] J. D. Mahony, D. M. Di Toro, A. M. Gonzalez et al., "Partitioning of metals to sediment organic carbon," Environmental Toxicology and Chemistry, vol. 15, no. 12, pp. 2187-2197, 1996. 
[14] U.S. Environmental Protection Agency, "Equilibrium partitioning approach to predicting metal bioavailability in sediments and the derivation of sediment quality criteria for metals. Briefing Report to the Science Advisory Board," EPA 822-D94-002, Office of Water, Office of Research and Development, Washington, DC, USA, 1994.

[15] D. F. Almeida, A. H. Martins, and J. G. Tundisi, "Weight-ofevidence on environmental impact assessment of metal contaminated sediments in the São Francisco River (Três Marias, Minas Gerais, Brazil) —a case study," Brazilian Journal of Biology, vol. 71, no. 4, pp. 961-973, 2011.

[16] A. Misi, S. S. S. Iyer, C. E. S. Coelho et al., "Sediment hosted lead-zinc deposits of the Neoproterozoic Bambuí Group and correlative sequences, São Francisco Craton, Brazil: a review and a possible metallogenic evolution model," Ore Geology Reviews, vol. 26, pp. 263-304, 2005. 

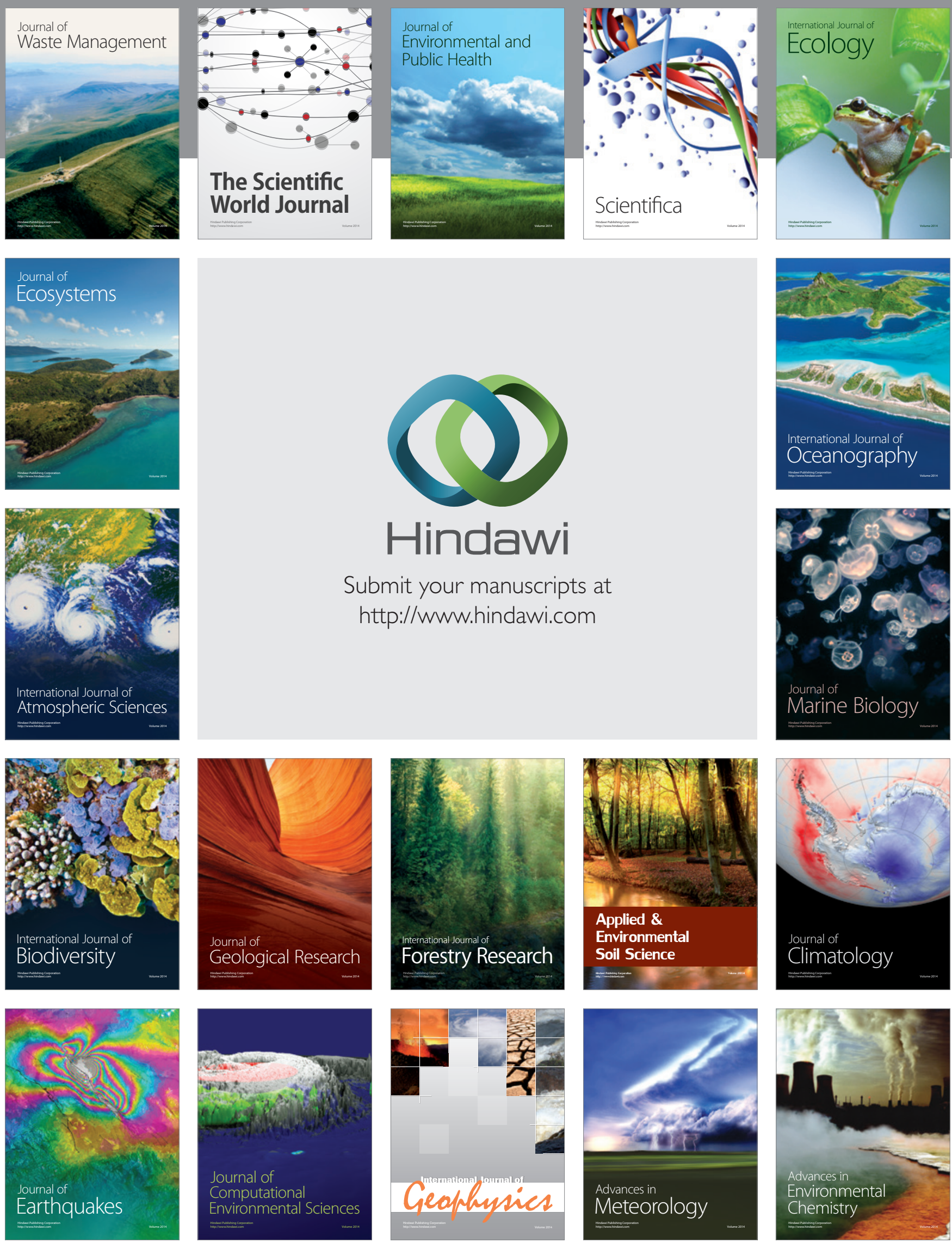